\title{
Capacity Building in Preparing the Health Workforce to Deliver the Digital Future
}

\author{
Sidsel VILLUMSEN ${ }^{\mathrm{a}, 1}$, Sascha ELSBERG ${ }^{\mathrm{b}}$, Celine LOVGREN $^{\mathrm{b}}$, Karina \\ VINTHER $^{\text {a }}$, Lise KLARHOLT BUSK ${ }^{\text {a }}$, Sigrid VEST ARLER ${ }^{\text {a }}$, and Ouafa RIAN ${ }^{\mathrm{a}}$ \\ ${ }^{\mathrm{a}}$ Koncern HR, Udvikling, Central Region Denmark, Aarhus, Denmark \\ ${ }^{\mathrm{b}}$ Department of Education Studies, Danish School of Education, Aarhus University, \\ Denmark
}

\begin{abstract}
Programs supporting the necessary combination of digital, organizational, and cultural transformational change, motivating and engaging the workforce, are scarce. This discussion paper reports on the initial experiences from a competency development program aiming at building capacity within the workforce, leaders, and organization in secondary healthcare to navigate and facilitate digitally transformative healthcare systems. The program aims to support employees and leaders who i) understand digitalization in and of practice, ii) reflect and approach digitalization in a critical and ethical way, iii) are curious and maintain a growth mind-set, iv) engage in development and implementation of digitalization, and v) can convey and communicate digitalization. The insights from the prototype can be useful in further promoting sustainable digitalization within healthcare and supporting leaders in their conduct and management of digital health initiatives.
\end{abstract}

Keywords. Competency development, digital skills, healthcare

\section{Introduction}

"When change is greater than learning, we are in trouble!" [1]. The rapid technological development necessitates the need to provide the workforce with broad frameworks or principles (i.e. mind-set), rather than in-depth experience with specific technologies or products [2]. New technologies change the ways in which we interact, work, and communicate, placing high demands for new competencies for all professions at both the employee and leadership level [3,4]. This requires both strategic directions for competence development as well as concrete and practice oriented programs and education directed at the daily practice of employees and leaders, encompassing both technological, cultural, and change management elements. However, such programs are scarce in Denmark. This discussion paper reports on the development and prototyping of a format to support cultural and digital transformational change, motivating and engaging the workforce in secondary healthcare in Central Region Denmark, one of five health regions in Denmark responsible for providing secondary healthcare for 1.3 million citizens. The insights and recommendations can inform further efforts in capacity building in preparing the health workforce to deliver the digital future.

${ }^{1}$ Corresponding Author, Sidsel Villumsen, Koncern HR, Udvikling, Central Region Denmark, Olof Palmes alle 32, DK-8200 Aarhus N, Denmark; E-mail: sidvil@rm.dk. 


\section{Prototype programs for capacity building}

In 2018, at the initiative of the Executive Board in Central Region Denmark, a survey was conducted on how to lead in digitalization processes - how leaders in the health region understood digitalization management and how they worked with it on a daily basis. Based on these findings, the project Leading in Digitalization was initiated to strengthen and support the leaders of Central Region Denmark (formal and informal) in relation to the development, implementation, and application of digital solutions, both within Central Region Denmark and across healthcare sectors.

The purpose of the project Leading in Digitalization was to develop and test a concept for improving competency and capacity to navigate digitalization among leaders in the healthcare system. The program was rooted in the HR Group (responsible for management development in the health region) and IT department, within the Central Region Denmark, and the first prototype was supported financially by the Danish Ministry of Health. The project aimed at expanding existing leadership programs with a particular focus on the management task of leading within an increasingly digitalized healthcare system, including i) providing an understanding of the technological opportunities and how the technology can effectively support workflows and good patient care, ii) to distribute methods for leading and activate processes for engaging citizens in the development and application of citizen-related digital technologies, iii) strengthening the skills to facilitate processes of digital change and transformation, iv) practice specific competencies in adopting and implementing digital solutions and tools, thereby acting as role models for other healthcare professionals, and v) to strengthen communication skills of leaders and employees in the context of digital transformation.

In 2019 the first prototype of the program was developed and tested [5]. Fifty board members, directors, managers, and key employees from all levels of management and with various experience in leading in digitalization participated. The first prototype consisted of two formats: one with management chains vertically engaged (i.e. hospital director, department management, daily management and key employees participating as a group) and one with participants out of pure curiosity and resonance (individual participation).

Based on the findings from the first prototype, a second prototype was devised, further informed by The Topol Review [4] and inspired by the efforts made by the NHS Digital Academy and NHS Health Education England [6]. The aims remained the same but the format was adapted to accommodate the insights gained from the first prototype; the main focus was on engaging vertical management chains as well as the individual and structural prerequisites to engage in the program [7].

Leading in Digitalization 2.0 takes departure in specific practice founded projects and in the individuals engaged in these projects, i.e. the project is the participating entity. The program offers module-based inspiration, knowledge, and tools, as well as sparring, facilitation, guidance, and process support for leaders and key employees throughout the process. During the program the project participants work to set clear goals and a catchy title, see the strategic development paths for the project, and reflect on which opportunities and challenges the project will encounter along the way. The participants gain experience with participant involvement, communication, implementation and digital imagination through five modules of each one day. The program spans approximately six months; the first four modules with one month intervals and the hind module approximately two months after. Table 1 describes the overall content of the modules. 
Table 1. Content of the five one-day modules in the program Leading in Digitalization

\begin{tabular}{|c|c|c|c|c|}
\hline Pre-module & $\begin{array}{l}\text { Citizens and } \\
\text { digitalization }\end{array}$ & $\begin{array}{l}\text { Culture and } \\
\text { Communication }\end{array}$ & Implementation & Hind module \\
\hline \multirow{6}{*}{$\begin{array}{l}\text { The problem } \\
\text { behind the } \\
\text { problem } \\
\text { Need statements } \\
\text { Business Model } \\
\text { Canvas }\end{array}$} & Digital personas & \multirow{2}{*}{$\begin{array}{l}\text { Turbo design } \\
\text { sprint }\end{array}$} & Pre-mortem & \multirow{2}{*}{$\begin{array}{l}\text { Presentation } \\
\text { mindset }\end{array}$} \\
\hline & Etnoraid & & Benefits & \\
\hline & Empathy mapping & Graphical & Management & \multirow{2}{*}{$\begin{array}{l}\text { Improvement } \\
\text { mentality }\end{array}$} \\
\hline & Patient ctorics & facilitation & Implementation & \\
\hline & & Storyboard & tools & \multirow{2}{*}{$\begin{array}{l}\text { Digital } \\
\text { imagination }\end{array}$} \\
\hline & $\begin{array}{l}\text { Citizen } \\
\text { involvement }\end{array}$ & $\begin{array}{l}\text { Digital } \\
\text { consideration }\end{array}$ & Case stories & \\
\hline
\end{tabular}

The format is highly interactive and the participants work on their projects throughout the modules culminating in a creative presentation of the projects process in the hind module. The projects were guided through a set of criteria throughout the program (see Table 2). Every project is assigned a multidisciplinary team, a "satellite", that facilitates and ensures a focus on communication, navigation, and interconnection, through guiding and supporting the management chains working on the specific projects. These satellites are designed to secure support and knowledge into the process - on the project's premises, culture, facilitation style, and based on the needs of the project.

Table 2. Criteria designed to ensure a connection between strategic initiatives and focus areas of the Central Denmark Region and management of the effort of digitalization.

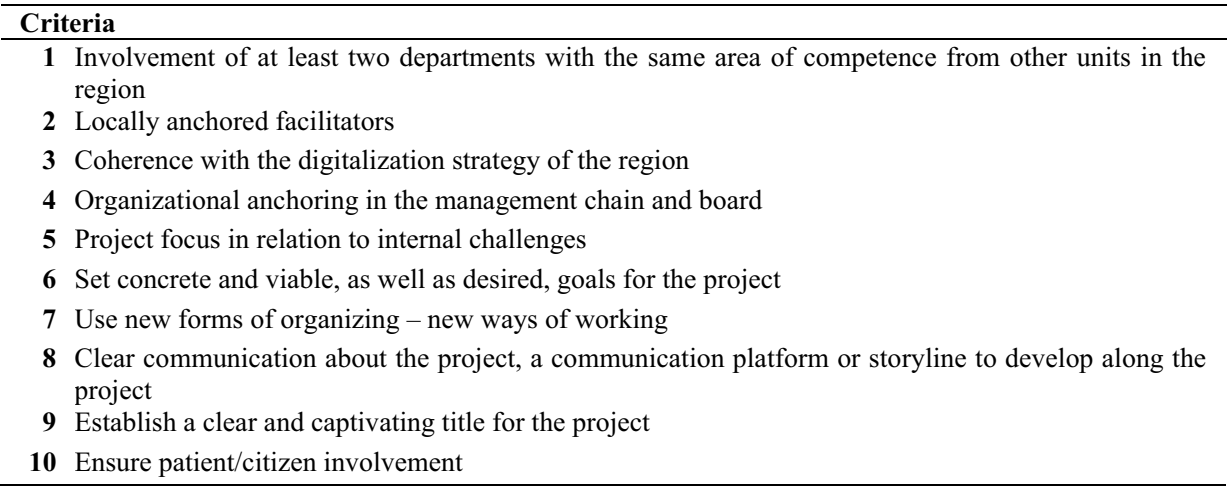

\section{Experiences so far}

The program was designed around three guiding structures: i) departure in specific, practise oriented projects, ii) participation as a vertical management chain, and iii) supporting systems for the individual projects during the program. By summer 2021 six different projects have participated in the program.

The insights and recommendations for capacity building are based on i) the design team's experience on how to support the people and organization in the process of attaining value creating digitalization, ii) participant self-scores, and iii) insights obtained through participant observations during the program as well group and individual interviews with participants and course managers conducted during spring 2021 by 
authors SE and CL for their master thesis in educational science. All participants gave informed consent prior to participating and data collection.

\subsection{Project oriented}

As the participants join the program with a project relevant in their daily practise, they are highly motivated in engaging in the program. Encompassing time to work in the project groups during the modules of the program was effective and appreciated by the participants. Participants emphasize that it was appreciated that the program allowed room for the projects to reflect and plan the project visions. As collaborative time is very often sparse in clinical practise, supporting the project groups with facilitated room for reflection and discussion is highly effective when aiming at supporting development and change. The participants used the course content within the course modules, applying it to their own project and process, which is conductive for transfer [8]. The participants applied both knowledge and methods between the modules in their daily practise, e.g. drawing story boards to facilitate communication and involvement from colleagues.

\subsection{Vertical management chain}

Participating as a vertical management chain appears beneficial for the implementation process and minimises the need for translation and transfer after the course modules, as it is common for other competence development programs. Vertical management chains are also relevant in decision making. Participants were not stopped in their processes because they had to wait and ask for permission - the decision competence and employee perspectives are integral parts of the project group allowing agile processes and seemingly enhancing motivation and job satisfaction.

\subsection{Supporting systems - Satellites}

The significance of the satellites is seen on several levels. As the satellites are comprised of people from across the organization (i.e. IT, HR etc.) as well as external capacities, the satellites provide valuable feedback and insight for the organization into how leaders and employees manage and navigate digitalization in practise. The format creates an agile, fast-moving and "in time" access to knowledge and network, as well as training in accessibility, to dare move beyond of culturally knowledge spheres and thereby expand the projects' and organizations self-understanding. From the project perspective, gaining value from the satellite requires engaged and relevant competencies in the satellite as well as alignment of expectations and continuous progress of the projects.

\section{Effects of the program and further development}

The participants increased their self-perceived ability to navigate the digital transformation of the health system, critical thinking on the processes in which digital solutions are implemented, and their understanding of how to manage digitalization. A strong focus on communication and cultural change and development alongside with the technical elements seem to be consistently important factors for all the projects. 


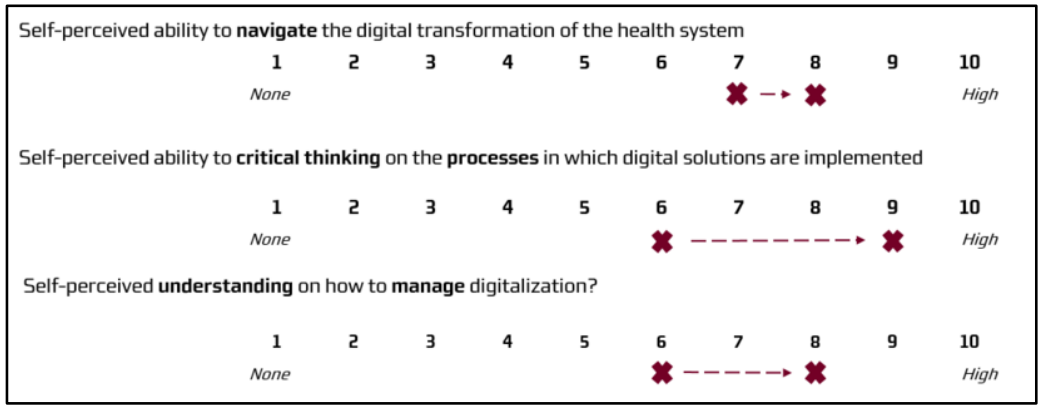

Figure 1: Median self-scores from participants based on 19 baseline answers and 16 follow up answers.

Despite having very different points of departure, the projects had achieved the goals they set initially and were working towards either more ambitious goals or to applying their solutions in different settings or contexts, thus supporting the transition towards delivering the digital future of healthcare.

In moving forward in developing and improving the prototype, particular attention should be given to specifying the role of management and leadership in the implementation phase as well as facilitating opportunities for leaders and employees to gain knowledge on relevant and emerging technologies, e.g. image recognition, machine learning, virtual reality etc. Revisiting the criteria throughout the program heightens the projects' self-awareness as well as supporting the implementation and dissemination. Supporting opportunities for exchange of experiences between the projects of the program in order to expand perspectives and cross fertilize ideas throughout the program is highly relevant and establishing network groups could be pertinent.

The prototype was an attempt to build capacity to support and address the digital and cultural transformation healthcare is facing. The initial experiences reported in this paper have been encompassed in the further development of the program. We encourage others to adopt a similar approach in building and developing programs focusing on promoting a combination of digital and cultural transformational change, motivating and engaging the health workforce to deliver the digital future.

\section{References}

[1] J.K. Bowerman, Action learning: The need for action and reflection for managers and learners in a world of change, J. East. Eur. Cent. Asian Res. 5 (2018). doi:10.15549/jeecar.v5i1.208.

[2] T. Foley, and J. Woollard, The digital future of mental healthcare and its workforce: a report on a mental health stakeholder engagement to inform the Topol Review, 2019.

[3] The Medical Futurist, 3 Reasons Why National Digital Health Transformations Fail, (2021). https://medicalfuturist.com/why-national-digital-health-transformations-fail/ (accessed July 7, 2021).

[4] E. Topol, The topol review: preparing the healthcare workforce to deliver the digital future (final report), 2019. https://topol.hee.nhs.uk/.

[5] Central Region Denmark, Prototype: Ledelse i Digitalisering (2019) - Region Midtjylland, (n.d.). https:/www.rm.dk/om-os/organisation/koncern-hr/uddannelse-udvikling-ogarbejdsmiljo/udvikling/ledelse-i-digitalisering/digi-wiki/ (accessed July 7, 2021).

[6] NHS Digital Academy | Health Education England, (n.d.). https://www.hee.nhs.uk/our-work/nhs-digitalacademy (accessed September 8, 2021).

[7] Central Region Denmark, Ledelse i Digitalisering 2.0 - Region Midtjylland, (n.d.). https://www.rm.dk/omos/organisation/koncern-hr/uddannelse-udvikling-og-arbejdsmiljo/udvikling/ledelse-idigitalisering/ledelse-i-digitalisering-20/ (accessed July 7, 2021).

[8] B. Wahlgren, and V. Aarkrog, Transfer: kompetence i en professionel sammenhæng, Aarhus Universitetsforlag, Aarhus, 2012. 